\title{
Lung Chondroma
}

National Cancer Institute

\section{Source}

National Cancer Institute. Lung Chondroma. NCI Thesaurus. Code C45629.

A benign neoplasm composed of hyaline cartilage arising from the lung. It is

characterized by the presence of chondrocytes, a lobulated growth pattern, and calcification. 